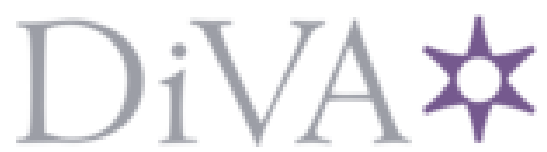

http://www.diva-portal.org

This is the published version of a paper published in Journal of Services Marketing.

Citation for the original published paper (version of record):

Kristensson, P. (2019)

Future service technologies and value creation

Journal of Services Marketing, 33(4): 502-506

https://doi.org/10.1108/JSM-01-2019-0031

Access to the published version may require subscription.

N.B. When citing this work, cite the original published paper.

(C) Per Kristensson. Published by Emerald Publishing Limited. This article is published under the Creative Commons Attribution (CC BY 4.0) licence. Anyone may reproduce, distribute, translate and create derivative works of this article (for both commercial and noncommercial purposes), subject to full attribution to the original publication and authors. The full terms of this licence may be seen at http://creativecommons.org/licences/ by/4.o/ legalcode

Permanent link to this version:

http://urn.kb.se/resolve?urn=urn:nbn:se:kau:diva-75115 


\title{
Future service technologies and value creation
}

\author{
Per Kristensson \\ CTF Service Research Center, Karlstad University, Karlstad, Sweden
}

\begin{abstract}
Purpose - The purpose of this paper is to propose a framework for understanding, predicting and analyzing how future service technologies can lead to value co-creation at different stages of a value chain.

Design/methodology/approach - For organizations, future service technologies are growing in importance and will become a crucial means to survival. It is clear that future service technologies will increase the opportunity to reduce costs and create efficiency, but it is not equally clear how future service technologies enable value creation for customers and users. On this premise, the study proposes a conceptual framework.

Findings - The framework illustrates how future service technologies can lead to value creation for customers. The paper also portrays opportunities and potential pitfalls with future service technologies for organizations.

Originality/value - Several researchers are focusing on innovative technologies. Many business companies are talking about how to implement them and increase their profit. However, less attention is devoted to the ways in which future service technologies will lead to benefits and the experience of service for customers and users using them. This paper represents an original attempt to illustrate that.
\end{abstract}

Keywords Customer value, Innovation, Service co-creation, Service dominant logic (SDL)

Paper type Viewpoint

\section{Introduction}

The standpoint for the commentary to this special issue is how customer and user value can potentially be improved by future service technologies. The commentary proposes the key message that future service technologies is not so much about the technology itself as it is about the benefits and the value it is intended to co-create. This key message implies that for new service technologies to be successful, the organizations implementing these services need to consider how they can benefit both the customer and the organization. The paradox is that if an organization focuses only on the benefits to itself, the benefits to customers are less likely to appear, which will have negative consequences for the organization.

Evidently, the rapid growth of future service technologies translates into a multitude of new opportunities for organizations, as well as for customers and users. The speed of technological advancement shaping today's services stresses the importance of rethinking how managers can diagnose and solve real-world problems and maintain customer-centricity. Thus, future service technologies have the opportunity to change how users are creating value in a dramatic way. By future service technologies I refer to new technological opportunities that improve the ability to co-create service with users. Value creation refers to how users (i.e. various kinds of actors, such as business customers, consumers, patients, citizens, etc.) are positively benefitting from usage of one or a combination of resources (e.g. offerings).

The current issue and full text archive of this journal is available on Emerald Insight at: www.emeraldinsight.com/0887-6045.htm

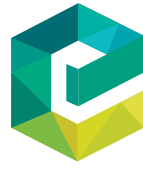

Journal of Services Marketing

33/4 (2019) 502-506

Emerald Publishing Limited [ISSN 0887-6045]

[DOI 10.1108/JSM-01-2019-0031]
To assist organizations in the challenging situation that future service technologies implies, researchers can investigate how customers can (self-) diagnose and solve problems that will be beneficial for themselves in their everyday lives. Researchers can also help by analyzing how future service technologies may increase the likelihood of personalization and be just the means to an end that customers need but may not always be capable of articulating (Huang and Rust, 2017). Researchers can also examine how business managers, with the help of new service technologies, can identify, monitor, regulate and solve important problems for customers, users, societies and the planet. Thus, research within this area is important and Kunz et al. (2019) have called for research that, while the rapid development of new service technologies is ongoing, can further advance our understanding of how technology can improve the lives for individuals and organizations. In response to Kunz et al.'s (2019) important call, this commentary presents a reflective framework aimed at examining how various future service technologies can accomplish customers to experience value creation.

\section{The future roles of new service technologies}

It is difficult to say how new service technologies will play an important role in customers' lives in the future. Consider the following: In a market research survey commissioned by AT\&T to McKinsey in the 1980 s, users were asked to predict their

(C) Per Kristensson. Published by Emerald Publishing Limited. This article is published under the Creative Commons Attribution (CC BY 4.0) licence. Anyone may reproduce, distribute, translate and create derivative works of this article (for both commercial and non-commercial purposes), subject to full attribution to the original publication and authors. The full terms of this licence may be seen at http://creativecommons.org/licences/ by/4.0/legalcode

Received 24 January 2019

Revised 24 January 2019

Accepted 28 January 2019 
need for a mobile phone in the future and the estimation turned out to be less than 1 per cent of the actual figure (economist. com). Consumers expressed that mobile phones had no place in their lives. Today we know that things turned out to be in the opposite direction. In a similar way, Gordon Moore, the founding CEO of Intel, noted that most of Intel's revenue came from a microprocessor that Intel internally did not regard as one of its top 50 market applications (Chesbrough, 2006). Kristensson et al. (2015) found that nurses predicted the value of new telemedicine equipment as low before usage. When they actually trialed the new technology for the first time, they rated the value significantly higher. Two weeks after the trial, the nurses again reported that they remembered the technology as less valuable. Thus, a possible conclusion is that future technologies may affect people in ways that are unthinkable in advance. We are simply too fixated to our current knowledge of how things are being done today to plan for the future in an innovative way (Kahneman and Tversky, 1979).

When it comes to future service technologies, there is a counter-intuitive flip side regarding innovation and its relation to value creation for customers (Snyder et al., 2016). Perhaps most notable is the somewhat neglected circumstance that technological innovation, when it involves a new offering, does not necessarily have to translate into any detectable value for a customer. For example, the latest iPhone with new OLEDdisplay, called super retina, provides more accurate color, referred to as "HDR" (high dynamic range), with true black nuances. For the general customer, however, this may only appear as an incremental improvement in picture accuracy, which likely is difficult to discern and therefore represents only a very small increase of experienced value for a customer. In addition, the history has given us an abundance of examples of new technologies that never created any value for customers or the innovating company. Conversely, Uber, a new form of taxi that is radically changing how customers are choosing to travel, involves very little new technological innovation. Instead, Uber introduced a new business model in combination with a mobile phone app. The story behind the success is easily available taxis at affordable prices that save customers time and money.

In this way, developing and implementing future service technologies always implies a balancing act for companies and organizations. As hinted above, the balance is between focusing too much on the technology in itself, where technology takes the representation of being the end rather than a means to an end, and customer or user value, where technology simply represents a means to an end. Although most marketers probably would point toward the latter, many researchers, not to mention managers, have focused on the technology itself and how to make it better. How the customer can have an improved life as a result of the technology is something that has been treated as self-evident or up to the customer. There is justification toward the former, as new technologies represent something new and exciting that we have not seen functioning or possible to make previously, while customer value typically remains the same, for example, saving one's time, saving money, providing safety, finding information and having fun.

There is a common problem when it comes to the introduction of new technology, most of which is the result of old and successful traditions in manufacturing. The old school of thought informed companies to ask themselves how they can make better products and how they can get customers to adopt these at an increasing rate. However, instead of asking what new technology customers would like to have, companies and organizations would do much better to ask how they better can support their customers or users to reach valuable outcomes in improved ways (Heinonen et al., 2010).

In service research, the perspective that has come to influence service marketing in the past decade suggests a new way of thinking. It states that rather than goods being exchanged for money, it is the activities emanating from an integration of resources, that customers are looking for (Vargo and Lusch, 2004a, 2004b; 2017). Thus, rather than asking for ownership of a new digital service in the form of a wearable t-shirt that can indicate one's blood pressure, the customer wants to be able to lean back and enjoy the fact that he/she knows he/she still is in good health. The implication of this new school of thought is that companies and organizations need to understand how new technology can improve the situation for customers, or organizations, in some way. This does not necessarily mean that the customers must be offered something new; the technology can, for instance, help the providing company to better predict fluctuations in demand or improve the ability to prevent break-downs.

\section{How future service technologies assist in value creation}

Below, I outline a framework illustrating a simplified valuechain to give my reflections a red thread (Berggren et al., 2008; Sawhney et al., 2006). The framework should exemplify and make it easier to understand, predict, and/or discuss how future service technologies can lead to the creation of new value. It should help customers as well as managers to ensure that customers are not forgotten when it comes to new technologies, and it should also indicate how usage of future service technologies can solve problems that are important for customers. In addition to providing structure to my thoughts, the framework makes an attempt to illustrate the infinite roles that new service technologies may play in the future. As the framework indicates, these situations are numerous, may also be hidden and, as concluded previously, are often therefore difficult to imagine beforehand. The examples of technology mentioned in the framework should be taken as illustrative examples for igniting inspiration. The most important aspect is that the framework emphasizes and illustrates the link between technology and value creation, as these two entities need to be married to each other in order for meaningful and long-term sustainable service to appear. The framework is displayed in Figure 1 and explained in more detail in the subsequent paragraphs.

\section{The first chain}

Figure 1 starts with the involvement of different actors, such as business partners and suppliers, and concerns the extent to which future service technologies can detect upcoming needs of input. New service technologies that detect future needs can facilitate (for example) just-in-time delivery or smoothen many types of operations that are typically found in industrial settings. New technologies, in terms of industrial internet of things, can detect sudden decreases in supply, automate new 
Figure 1 Future service technologies facilitating value creation in different phases of a value chain

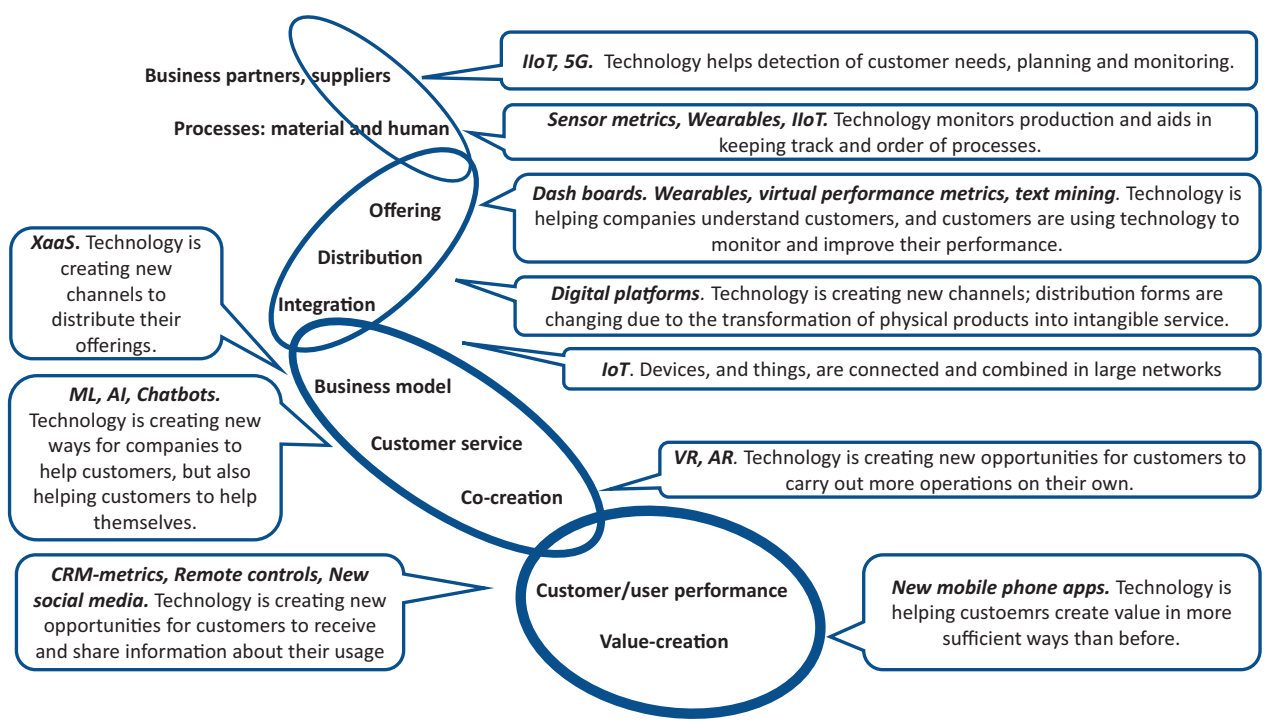

orders, or remotely regulate processes through $5 G$ network connections. The benefit of future service technology, as displayed at the top of Figure 1, may regard improved aid in detection of customer needs, planning and monitoring.

Moving further in the value chain to business processes raises questions such as to what extent technology can help keep track of production, how machines are performing, and how things are dispersed outside the factory or plant. Here, new technologies can aid in detection and positioning, which can be important to prevent breakdown. New technologies can be used not only to serve control of material processes, but also human ones. In this regard, technology can display how employees are performing. For example, technology may alert front-line employees when customers are about to approach or how many times a certain process has been run by a customer. Information of this kind can improve preparation for customer service and delivery. For both these cases (i.e. material and human), future service technologies may deal with different types of wearables and sensor metrics that can aid managerial and organizational decision-making. Cloud-based software infrastructure can be used to measure, collect and store big data. In sum, technology is helping both the customer and the providing organization to keep order and track of processes.

\section{The second chain}

Approaching the middle section of Figure 1, the offering comes into focus. Here, future service technologies can be used to indicate how the offering is performing during usage, that is, when and where the customers are using the offering and the total usage time. So-called up- and down-time can be monitored and also how customers are becoming more proficient at using the offering over time. These are all examples of how future technology can assist customers' value creation. This is important because improved understanding of how customers are co-creating value represents a cornerstone in the success of any business or organization (Kunz et al., 2017). Examples of future service technologies may involve data dash-boarding, where customer behavior is visualized in real-time and during customer value co-creation. Text mining can imply opportunities for companies to better understand customer behavior.

Regarding distribution, an increasingly important issue is whether technology can transform physical goods into intangible service. Examples of future service technologies involve new platforms and big data access, where offerings that were previously tangible are made intangible (Lusch \& Nambisan, 2015). It is notable how the entire music industry has transformed into a streamed service that customers subscribe to, instead of buying physical goods in one-time transactions in retail stores. In this way, new service technologies are implying opportunities to create new channels and distribution forms.

Integration is an important aspect of new technology as it will be possible to connect many future innovations to each other. For example, technology can show how solutions from one company are interacting or being used with solutions from other companies. If so, future service technologies can facilitate in managing the integration of resources in a way that is beneficial for the customer. Examples may involve a new internet of things where devices transmit information and detect each other. With the increasingly popular term "Industry 4.0," one of the main characterizing features is that machines interact with each other (Lorenz et al., 2015).

\section{The third chain}

Regarding new business models, future service technology may imply opportunities for how companies can make revenue and, at the same time, facilitate for customers to enable (for example, smoothen their purchase process). Examples may involve new service business models such as XaaS (i.e. anythingas-a-service) where customers subscribe to or hire services instead of making a large one-time transaction of physical products.

A traditional value-chain focuses on activities occurring within the organization. As this commentary wants to raise awareness about circumstances in which customer processes 
are often neglected, this value chain is extended with activities relating to customer value (Porter and Kramer, 2011). Thus, a value chain should also involve user value.

Approaching the bottom of the Figure 1, the focus shifts to how future service technology can support customer service and imply new ways of communication and interaction. Future service technologies are likely to involve chatbots, machine learning (ML) and artificial intelligence (AI) to interact and train customers to get more out of their offerings than what has previously been the case. In particular, ML and AI can be used to help customers become more proficient at carrying out performances in the future. Here, technology can assist in creating new ways for companies to help customers but also for customers to help themselves.

In terms of co-creation, future service technologies are likely to imply many new opportunities for customers to carry out more operations on their own. When more value co-creation activities can be carried out by customers themselves, opportunities in terms of personalization increase. Also, customers can test-run and train new services by means of future service technologies. In this regard, technological innovations such as virtual reality and augmented reality can be expected to be important.

\section{The fourth chain}

As mentioned previously, future service technology can be used to indicate customer performance improvement over time. Technology is creating opportunities for customers to receive and share information about their usage. Data displays that allow users to improve, become smarter or save money are likely to be increasingly in demand. Examples of future service technologies may involve new CRM metrics, remote-control devices, sharing of knowledge by means of social media, or the above-mentioned data dashboards. All these can enable customers to see how they are performing while they are using different types of offerings (Fan and Gordon, 2014). Similarly, new social media analytics may indicate how other users are experiencing same or other types of activities. The result of future service technologies is that the customer will be able to carry out more and more operations on their own in an increasingly professional manner.

Finally, as mentioned in the introduction to this commentary, future service technologies exist for a reason, namely, to assist in improving value creation. How can future service technologies be used so that customers' lives improve or become more efficient? Can technology display how and when value is being experienced? Future service technologies can provide information about how much time a customer is saving or how much cleaner the environment is becoming when a customer is performing a certain activity. Examples of future service technologies may involve real-time usage of metrics and data analytics that are easily available, for example, through mobile phone apps or similar. The bottom line is that technology is helping the customer to co-create value in a more sufficient way than before.

\section{Concluding remarks}

Overall, Figure 1 conveys how it could be possible to use future service technologies as a means to an end, which in these terms means supporting customer value creation. Although the providing service company in several of the instances is the possessor and user of new service technologies, Figure 1 illustrates how customers will still benefit from the technology in the end. The implementation of future service technologies in the way that is illustrated in the Figure is believed to increase the likelihood of leading to customers that are satisfied and will therefore be retained, which will imply value capturing for companies as well (Keiningham et al., 2017). In this way, future service technologies have the capacity to create a win-win situation for both companies and customers.

However, future service technologies are not always beneficial for companies or customers. As mentioned, history is full of examples where new innovations have failed to both provide customers and companies with any value at all. Customer might lack skills and knowledge, or motivation, and therefore not be able to use the technology in the intended way. Future service technologies can also serve the role of only improving the situation for the company, while things will remain the same for the customer. A new technology can imply a way of saving costs for the company, while customers receive the same service as they had previously. This would imply facilitating companies to improve their profit margin, given that the same service at the same price is delivered to the customer as before.

\section{References}

Berggren, U., Bergkvist, T. and Hedby, U. (2008), De Nya Affärsinnovationerna (the New Business Innovations), Nutek, Sweden.

Chesbrough, H. (2006), Open Business Models: How to Thrive in the New Innovation Landscape, Harvard Business Press, USA.

Fan, W. and Gordon, M.D. (2014), "The power of social media analytics", Communications of the ACM, Vol. 57 No. 6, pp. 74-81.

Heinonen, K., Strandvik, T., Mickelsson, K.-J., Edvardsson, B., Sundström, E. and Andersson, P. (2010), “A customer dominant logic of service", Fournal of Service Management, Vol. 21 No. 4, pp. 531-548.

Huang, M.H. and Rust, R.T. (2017), "Technology-driven service strategy", Fournal of the Academy of Marketing Science, Vol. 45 No. 6, pp. 906-924.

Kahneman, D. and Tversky, A. (1979), "Intuitive prediction: biases and corrective procedures", TIMS Studies in Management Science, Vol. 12, pp. 313-327.

Keiningham, T., Ball, J., Benoit, S., Bruce, H.L., Buoye, A., Dzenkovska, J. and Zaki, M. (2017), "The interplay of customer experience and commitment", fournal of Services Marketing, Vol. 31 No. 2, pp. 361-384.

Kristensson, P., Brunstrom, A. and Pedersen, T. (2015), "Affective forecasting of value creation: professional nurses' ability to predict and remember the experienced value of a telemedicine diagnostics ICT service", Behaviour \& Information Technology, Vol. 34 No. 10, pp. 964-975.

Kunz, W., Aksoy, L., Bart, Y., Heinonen, K., Kabadayı, S., Ordenes, F.V. and Theodoulidis, B. (2017), "Customer engagement in a big data world", Fournal of Services Marketing, Vol. 31 No. 2, pp. 161-171.

Kunz, W., Heinonen, K. and Lemmink, J. (2019), "Future service technologies: is service research on track with 
business reality?", fournal of Services Marketing, Vol. 33 No. 2.

Lorenz, M., Ruessmann, M., Strack, R., Lueth, K.L. and Bolle, M. (2015), Man and Machine in Industry 4.0: How Will Technology Transform the Industrial Workforce through 2025, The Boston Consulting Group.

Lusch, R.F. and Nambisan, S. (2015), "Service innovation: a service-dominant logic perspective", MIS Quarterly, Vol. 39 No. 1.

Porter, M.E. and Kramer, M.R. (2011), "The big idea: creating shared value", Harvard Business Review, pp. 1-17.

Sawhney, M., Wolcott, R.C. and Arroniz, I. (2006), "The 12 different ways for companies to innovate", MIT Sloan Management Review, Vol. 47 No. 3, pp. 75.

Snyder, H., Witell, L., Gustafsson, A., Fombelle, P. and Kristensson, P. (2016), "Identifying categories of service innovation: a review and synthesis of the literature", fournal of Business Research, Vol. 69 No. 7, pp. 2401-2408.

Vargo, S.L. and Lusch, R.F. (2004a), "Evolving to a new dominant logic for marketing", fournal of Marketing, Vol. 68 No. 1, pp. 1-17.

Vargo, S.L. and Lusch, R.F. (2004b), "The four service marketing myths: remnants", Of a Goods-Based,
Manufacturing Model. Fournal of Service Research, Vol. 6 No. 4, pp. 324-335.

Vargo, S.L. and Lusch, R.F. (2017), "Service-dominant logic 2025", International fournal of Research in Marketing, Vol. 34 No. 1, pp. 46-67.

\section{Further reading}

Kaplinsky, R. and Morris, M. (2000), A Handbook for Value Chain Research, University of Sussex, Institute of Development Studies, Vol. 113.

The Economist (1999), "Cutting the cord", available at: www. economist.com/special-report/1999/10/07/cutting-the-cord

\section{About the author}

Dr Per Kristensson is a Professor and the Director at CTF, Service Research Center, Karlstad University, Karlstad, Sweden. $\mathrm{He}$ is also a Visiting Professor at CSI, Center for Service Innovation, NHH, Norges HandelsHöyskole in Bergen, Norway. Per Kristensson can be contacted at: per.kristensson@kau.se

For instructions on how to order reprints of this article, please visit our website:

www.emeraldgrouppublishing.com/licensing/reprints.htm

Or contact us for further details: permissions@emeraldinsight.com 